\title{
HÉRNIA TRAUMÁTICA DA PAREDE ABDOMINAL TRAUMATIC ABDOMINAL HERNIA
}

\author{
Alexandre Cruz Henriques, TCBC-SP ${ }^{1}$ \\ Simone Chiconelli Henriques, ACBC-SP ${ }^{2}$ \\ Carlos Alberto Godinho ${ }^{3}$
}

\section{INTRODUÇÃO}

A hérnia traumática da parede abdominal (HTPA) permanece uma entidade clínica rara a despeito do aumento da incidência do trauma abdominal fechado. ${ }^{1}$ Isto se deve provavelmente à natureza elástica da parede abdominal e à necessidade da combinação de mecanismos específicos para produzir tal defeito. ${ }^{1,2}$ Devido à sua raridade, muitas vezes o diagnóstico não é lembrado, protelando o tratamento adequado; sempre que possível, a cirurgia deve ser realizada precocemente, na fase aguda. $\mathrm{Na}$ fase tardia existe o risco de encarceramento, maior dificuldade técnica na operação e possibilidade do emprego de tela para reconstrução da parede. ${ }^{3}$

Tendo vivenciado um caso de paciente portador de volumosa HTPA em flanco direito, devido à sua raridade julgamos oportuno relatá-lo.

\section{RELATO DO CASO}

Doente do sexo masculino, 60 anos, com queixa de tumor em flanco direito, que se exarcebava em pé e que se reduzia em decúbito lateral esquerdo. Tinha como antecedente, grave acidente automobilístico há sete anos, no qual utilizava cinto de segurança, com fraturas no fêmur direito, no antebraço esquerdo e na tíbia esquerda. Todas as fraturas necessitaram de tratamento cirúrgico com colocação de placas. Permaneceu acamado durante um ano, quando começou a deambular com muletas. Após seis meses do acidente, notou abaulamento no flanco direito, que se acentuava aos esforços e que apresentou crescimento progressivo. Foi feito o diagnóstico de hérnia, e dois anos após o trauma foi operado. Um ano após houve recidiva da hérnia, que novamente passou a crescer progressivamente. Após cinco anos da tentativa de correção da hérnia, o doente procurou nosso serviço; o exame físico mostrava volumoso tumor em flanco direito medindo aproxi- madamente $17 \mathrm{~cm}$, com cicatriz cirúrgica antiga sobre o seu maior eixo, facilmente redutível com manobras manuais e no qual eram audíveis ruídos hidroaéreos. A tomografia computadorizada de abdome mostrou solução de continuidade na parede ântero-lateral do abdome por onde se exteriorizavam alças de intestino delgado (Figuras 1A e 1B). Foi feito então o diagnóstico de HTPA recidivada e indicada a operação.

O doente foi posicionado em decúbito lateral esquerdo. Após ampla incisão sobre o tumor herniário, o saco herniário foi dissecado da pele e da tela subcutânea; seu conteúdo foi reduzido e seu excesso, ressecado; observou-se que a musculatura ântero-lateral do abdome havia se desinserido parcialmente da crista ilíaca, provocando a falha por onde se desenvolvia a hérnia. Para corrigir o defeito optou-se por colocar tela de polipropileno (com dimensão maior do que o defeito muscular) sobre o saco peritoneal e que se estendia anterior e cranialmente sob a musculatura ântero-lateral do abdome, caudalmente pela face interna do osso ilíaco e posteriormente até o músculo psoas (Figuras 2A e 2B). Realizouse drenagem por aspiração após fechamento da tela subcutânea e da pele. A evolução foi sem complicações. Revisto após quatro meses, não apresentava sinais de recidiva.

\section{DISCUSSÃO}

A HTPA é definida como aquela que se faz através do esgarçamento da musculatura abdominal e suas fáscias, após trauma localizado, sem lesão penetrante da pele e sem evidência de hérnia anterior no local. A hérnia pode aparecer imediata ou tardiamente e, por isso, no ato operatório pode se encontrar ou não saco peritoneal..$^{2,4}$

O trauma abdominal fechado geralmente lesa vísceras situadas no interior da cavidade, estruturas ósseas ou o diafragma; a lesão da parede produzindo HTPA é evento raro, existindo menos de sessenta casos descritos na literatura até

\footnotetext{
1. Professor Assistente do Departamento de Cirurgia da Faculdade de Medicina do ABC. Cirurgião do Serviço de Cirurgia Geral da Intermédica Sistema de Saúde - Hospital Príncipe Humberto.

2. Cirurgião do Serviço de Cirurgia Geral da Intermédica Sistema de Saúde - Hospital Príncipe Humberto.

3. Médico Colaborador do Departamento de Cirurgia da Faculdade de Medicina do ABC.
}

Recebido em 16/12/98

Aceito para publicação em 13/9/99

Trabalho realizado no Serviço de Cirurgia Geral da Intermédica Sistema de Saúde - Hospital Príncipe Humberto. 


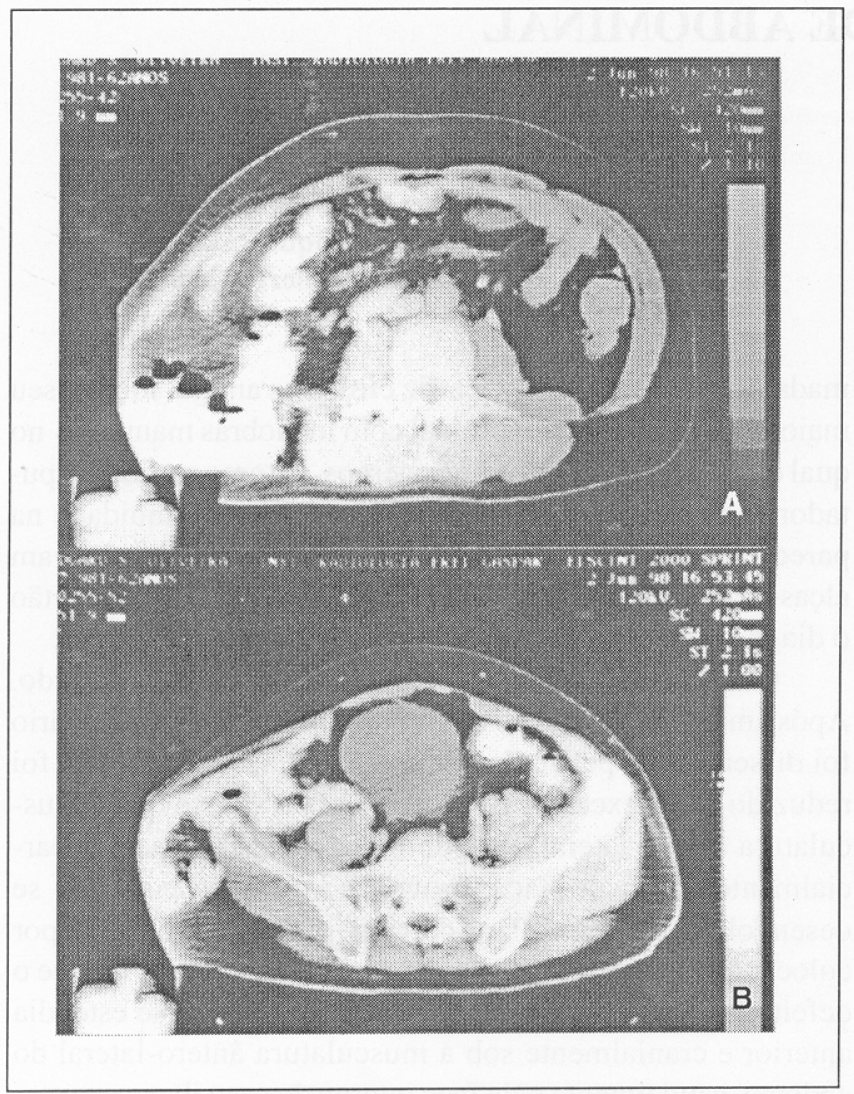

Figura 1A - TC mostrando musculatura ântero-lateral do abdome à esquerda íntegra, esgarçamento da mesma à direita e protrusão de alças intestinais para a tela subcutânea.1B - TC em corte mais baixo mostrando protrusão de alças intestinais sobre o osso ilíaco

1998. ${ }^{4}$ A causa mais comum de HTPA é o acidente de automóvel quando se usa cinto de segurança e em geral nestes casos, são produzidos grandes defeitos em qualquer quadrante na parede abdominal. A seguir, em freqüência temos as hérnias traumáticas causadas por pequenos objetos rombos (tipicamente o guidão de bicicleta), que produzem defeitos menores na parede, geralmente nos quadrantes inferiores do abdome. Estas lesões são causadas por um objeto que não é tão pequeno que penetre a pele e nem tão grande que disperse a energia cinética numa grande superfície. As forças aplicadas de maneira tangencial à parede produzem esgarçamento da musculatura; a pele, sendo uma estrutura elástica, permanece íntegra; a contração da musculatura abdominal contribui no mecanismo de lesão, uma vez que aumenta a pressão intra-abdominal e aumenta a relativa inelasticidade da musculatura. ${ }^{2}$ Nas grandes hérnias causadas por acidente de veículos, o aumento da pressão abdominal desempenha papel importante na gênese do defeito e quando este mecanismo age isoladamente, a lesão característica é a hérnia diafragmática esquerda. Cintos de segurança aplicados sobre a crista ilíaca (ou quando o paciente "desliza" sob o cinto) têm sido responsabilizados pela produção da HTPA; o mecanismo

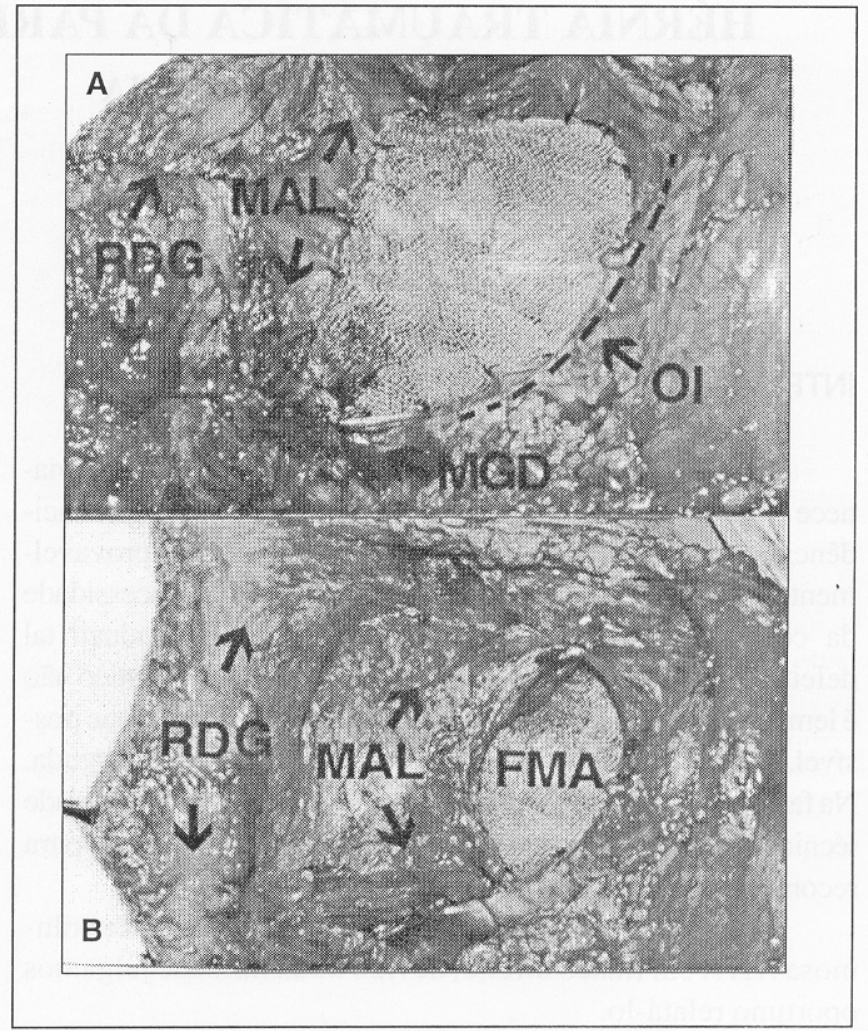

Figura $2 A$ e $2 B-$ Aspecto intraoperatório.

$R D G$ - Retalho dermo-gorduroso; $M A L$ - Musculatura ânterolateral do abdome; $M G D$ - Músculo grande dorsal; OI-Osso ilíaco; FMA - Falha músculo aponeurótica.

$2 A-R D G$ e MAL rebatidos, mostrando a colocação da tela sob estas estruturas. $2 B$ - Aspecto final da reconstrução da parede, mostrando a desinserção da MAL do OI, e a tela reforçando a FMA.

de lesão, nestes casos, envolve tanto o aumento de pressão intra-abdominal quanto a ação direta do cinto sobre a parede, que provocaria a avulsão da musculatura da sua inserção na bacia. $^{2}$

Quando a HTPA situa-se acima do umbigo, ocorrem lesões de vísceras intra-abdominais em aproximadamente $30 \%$ dos casos, sendo estas as principais responsáveis pela mortalidade. ${ }^{2,5}$

O diagnóstico de HTPA deve ser considerado sempre que o trauma tenha sido provocado por um objeto rombo de tamanho moderado, aplicado de maneira tangencial, e também nos acidentes de veículos associados a contusões relacionadas ao uso de cinto de segurança. Na fase aguda, o exame físico mostrará um empastamento doloroso na parede abdominal, que se acentua com a manobra de Valsalva ou com a posição do doente; a pele que recobre está edemaciada e equimótica;' outras vezes, o paciente encontra-se em abdome agudo em virtude de lesão visceral e o diagnóstico da HTPA é realizado durante a laparotomia. ${ }^{4}$

$\mathrm{Na}$ fase crônica, o exame físico revela com facilidade a existência de HTPA, como observado em nosso caso. As 
radiografias contrastadas do tubo digestivo e a tomografia computadorizada confirmam o diagnóstico; a última mostra com clareza a presença de alças intestinais na tela subcutânea e o defeito na musculatura abdominal. ${ }^{5}$ O diagnóstico diferencial deve ser feito com hema-toma do músculo reto e com hérnia preexistente. ${ }^{1}$

O tratamento da HTPA é cirúrgico e sempre que possível deve ser realizado precocemente, na fase aguda, através de uma incisão longitudinal: isto permite inventariar a cavidade a procura de lesões viscerais associadas e previne complicações como o encarceramento e estrangulamento; nesta fase, a síntese do defeito da parede abdominal tende a ser mais fácil, porque ainda não ocorreu retração dos tecidos. ${ }^{2} \mathrm{~A}$ correção cirúrgica deve ser retardada quando se tratar de paciente grave com lesões importantes em outros segmentos corporais (desde que não coexista lesão de víscera intra-abdominal) ou quando se tratar de cirurgia intensamente contaminada. A cirurgia deve obedecer aos princípios técnicos obrigatórios para a correção das hérnias em geral: identificação das bordas músculo-aponeuróticas íntegras e bem vascularizadas e aproximação das mesmas, sem tensão, por sutura com fios inabsorvíveis.

Quando a cirurgia é retardada, a incisão pode ser feita diretamente sobre o tumor herniário e, com freqüência, tornase necesário o uso de uma prótese para a adequada correção do defeito, devido à retração das bordas músculo-aponeuróticas. $^{2}$

No nosso caso, devido às grandes dimensões do defeito e por se tratar de reoperação, optamos por uma ampla via de acesso diretamente sobre o tumor herniário; após tratamento do saco herniário e dissecção das bordas músculo-aponeuróticas, colocamos uma tela de polipropileno, maior do que o defeito da parede, sobre o peritônio e sob as estruturas músculo-aponeuróticas.

O prognóstico geralmente é bom e está na dependência da existência de lesões associadas. ${ }^{2,5}$

\begin{abstract}
A rare case of blunt traumatic abdominal hernia is presented in which jejunal loops herniated through the abdominal wall. The patient had a serious motor vehicle accident seven years ago, while wearing the seat belt. He developed a traumatic hernia in the anterior lateral abdominal wall, which was operated, and relapsed after some months. The patient was reoperated and we observed the unattachment of the anterior lateral abdominal musculature from the ilium crest. After the hernial sac treatment, the defect was solved with the use of a polypropylene mesh. The postoperative evolution was good and four months later there were no signs of recurrence. Traumatic abdominal hernia remains a rare clinical entity, despite the increase in blunt abdominal trauma. Traumatic abdominal wall hernia falls into two general categories: small lower quadrant abdominal defects, typically the result of blunt trauma with bicycle handlebars, and larger abdominal wall defects related to motor vehicle accidents. The diagnosis may be often established by the physical examination alone. Conventional radiology and computerized tomography usefulness have been proved. In the vast majority of cases, early repair is recommended. The appropriate treatment is the reduction of the herniated bowel into the abdomen, the debridment of nonviable tissues, and a primary tension-free closure of the defect.
\end{abstract}

Key Words: Abdominal hernias; Trauma.

\section{REFERÊNCIAS}

1. Ciftci AO, Salman B, Türken A, et al - Acute blunt traumatic abdominal hernia. J Pediatr Surg 1997;32:1.732-1.734.

2. Wood RJ, Ney AL, Bubrick MP - Traumatic abdominal hernia: a case report and review of the literature. Am Surg 1988;54:648-650.

3. Nadal SR, Guedes MAC, Silva CRA, et al - Hérnia traumática da parede abdominal. Rev Col Bras Cir 1995;5:296-8.

4. Perez VM, McDonald AD, Ghani A, et al - Handlebar hernia: a rare traumatic abdominal wal hernia. J Trauma 1998;44:568-569.

5. Ganchi PA, Orgill DP - Autopenetrating hernia: a novel form of traumatic abdominal wall hernia - case report and review of the literature. J Trauma 1996;41:1.064-1.066

\author{
ENDEREÇO PARA CORRESPONDÊNCIA \\ Dr. Alexandre Cruz Henriques \\ Rua Mediterrâneo, 928 - Jardim do Mar \\ 09750-420 - São Bernardo do Campo - SP
}

